\title{
PROFESSORES EM EXAME: reflexões sobre politicas de avaliação docente
}

\section{TEACHERS UNDER EXAMINATION: reflections on teacher assessment policies}

\author{
Eneida Oto Shiroma* \\ Mara Cristina Schneider**
}

\begin{abstract}
Resumo
Este artigo discute as recentes propostas para a avaliação de professores no Brasil. Com base no materialismo histórico, analisamos documentos nacionais e internacionais para identificar os objetivos desse tipo de avaliação, as justificativas para sua implementação e os debates em torno de seus resultados. Constatamos convergências entre as políticas recomendadas pelo Banco Mundial e pela Organização para Cooperação e Desenvolvimento Econômicos e as propostas no Brasil, o que indica o grande interesse e influência dos organismos multilaterais na definição de políticas para os professores. As primeiras reações dos docentes, pesquisadores, associações de professores e instituições formadoras, acrescidas das experiências de outros países que adotaram políticas de avaliação de professores, nos ajudam a compreender os possíveis resultados e implicações dessas políticas para a categoria dos professores, suas carreiras e sindicatos.
\end{abstract}

Palavras-chave: Política educacional. Avaliação docente. Exame Nacional de Ingresso na Carreira Docente.

\begin{abstract}
This article discusses the current proposals of teacher assessment in Brazil. Based on historical materialism, we analysed national and international documents aiming at identifying the goals of this sort of assessment, the justifications for its implementation and debates about its outcomes. We found convergences between the policies recommended by the multilateral agencies, especially by the World Bank and the Organization for Economic Co-operation and Development, and those adopted in Brazil, which indicates the great interest and influence of multilateral organizations in the development of policies for teachers. The first reactions of teachers, researchers, teacher associations and training institutions, added to the experiences of other countries that have adopted teacher assessment policies earlier, help us to understand possible outcomes and implications of these policies for teachers as a class, their careers and unions.
\end{abstract}

Keywords: Educational policy. Teacher assessment. National Entrance Exam for Teachers.

\section{Introdução}

O interesse em melhorar o desempenho dos alunos e elevar os indicadores educacionais motiva alguns governos a promoverem reformas educacionais priorizando ações sobre os docentes. A formulação de políticas educacionais nacionais é amplamente influenciada por recomendações de organismos multilaterais como o Banco Mundial, que enfatiza a importância das políticas de avaliação e certificação dos docentes. (SCHNEIDER, 2009; DELLANOY; SEDLACEK, 2000). Há mais de duas décadas, Mello $(1990)^{1}$ defende a necessidade de

\footnotetext{
* Professora doutora da Universidade Federal de Santa Catarina. E-mail: eneidashiroma@gmail.com

** Doutoranda do PPGE da UFSC. Bolsista da CAPES. E-mail: maraefra@gmail.com

${ }^{1}$ Guiomar Namo de Mello foi secretária municipal de Educação
}

submeter os professores a um exame para obtenção de registro junto ao Estado. Para a autora, no Brasil não havia "cobrança e responsabilização", mecanismos de "controle e fiscalização" no ensino e "avaliação de resultados". (MELLO, 1990, p. 24-25).

Esses temas incipientes no debate educacional brasileiro de 1990 estão, agora, na ordem do dia. Desde 2007 tramita no Senado Federal e, em 2010, na Câmara dos Deputados, um projeto para instituir \begin{tabular}{l}
\hline e deputada estadual de São Paulo. Foi consultora do Banco \\
Mundial e trabalhou como especialista sênior para o Banco Inte- \\
ramericano de Desenvolvimento. Foi membro do Conselho Na- \\
cional de Educação. Em 1997, assumiu a direção executiva da \\
Fundação Victor Civita, organização que se dedica a publicaçães \\
especializadas para professores de Educação Básica e é man- \\
tida pelo Grupo Abril. Concomitantemente, dirigiu o editorial da \\
Revista Nova Escola, publicada pela Editora Abril. Foi diretora da \\
Escola Brasileira de Professores, empresa dedicada a estudos, \\
consultorias, iniciativas e projetos na área da formação inicial e \\
continuada de professores da Educação Básica. (MELLO, 2011).
\end{tabular} 
o Exame Nacional de Avaliação do Magistério da Educação Básica (ENAMEB) para fins de ingresso e progressão funcional na carreira. Ainda em 2010, o ministro da Educação Fernando Haddad institui o Exame Nacional de Ingresso na Carreira Docente, via Portaria $n^{0} 14$, para subsidiar os entes federados na realização de concursos públicos e contratação de professores. (BRASIL, 2010c).

Este artigo aborda as políticas que pretendem colocar os professores "à prova" por meio da realização de exames de avaliação e certificação para fins de ingresso e promoção na carreira. Por meio de uma pesquisa documental realizamos levantamento dos documentos nacionais que recomendam, desde 2003, a avaliação dos docentes no Brasil, identificando seus proponentes, objetivos e finalidades anunciadas. Sistematizamos os argumentos para a implantação das políticas de avaliação e analisamos as contradições e embates produzidos nesse processo.

Utilizando o materialismo histórico como referencial teórico-metodológico, apresentamos a gênese desse debate no Brasil e mapeamos na documentação de organismos multilaterais as influências internacionais para a formulação de políticas para professores.

\section{A lógica da certificação de competências: do setor produtivo para o educacional}

A proposta de certificação de competências tem origem na França no início dos anos 1970, quando o movimento operário reivindicava o "reconhecimento de seus saberes adquiridos na prática profissional como forma de garantir certa mobilidade na grade de classificação das empresas". (SANTOS; FIDALGO, 2004, p. 2). A partir de 1980, os empresários percebem a possibilidade de usar a certificação de competências como estratégia de reconversão dos trabalhadores para dotá-los de novos requisitos demandados pela reestruturação produtiva. No contexto da globalização, receitas para elevar a produtividade e capazes de potencializar as vantagens competitivas das empresas foram rápida e amplamente difundidas. É interessante observar como o capital transformou essa reivindicação original dos trabalhadores em uma ferramenta de gestão, visando atender aos interesses particulares de sua classe, aparentando atender aos dos trabalhadores. Esse movimento contribuiu para construir consenso em torno dos benefícios da certificação para ambos, capital e trabalho. Sob a justificativa de otimizar os serviços públicos, melhorar sua eficiência e qualidade, os mecanismos de avaliação e certificação de competências foram gradativamente introduzidos também no setor público, atrelados à remuneração por desempenho.
A certificação de competências e a avaliação de desempenho foram implantadas nas instituições públicas, sobretudo após a Reforma Gerencial do Estado $^{2}$ iniciada na primeira gestão de Fernando Henrique Cardoso (1995-1998). (SCHNEIDER, 2009). Os apologistas da reforma justificaram a necessidade de a administração pública adotar conceitos e ferramentas de avaliação da qualidade do setor produtivo apoiados na "crítica ao centralismo, à burocracia e ao déficit de qualidade dos serviços públicos". (BARROSO, 2005, p. 740).

Mello (2000, p. 119) defende que iniciativas oriundas do setor produtivo como a certificação de competências são relevantes para o campo educacional porque exercem "grande impacto para aferir a atualização e a educação continuada do professor e, ao mesmo tempo, impor parâmetros para o ingresso, a progressão na carreira e a remuneração do docente". As proposições de Mello reproduzem no país as recomendações do Banco Mundial (BM) que, em 2000, divulga um relatório específico sobre a situação dos docentes no Brasil, intitulado Brazil: teachers development and incentives: a strategic framework. Seus elaboradores, Dellanoy e Sedlacek (2000), ressaltam a necessidade de se produzir um novo tipo de professor, isto é, um professor competente, eficaz, equipado com um amplo repertório de estratégias de ensino, profundo conhecimento de conteúdo e um novo conjunto de valores, enfatizando a colaboração entre pares, a reflexão contínua sobre sua prática de ensino e a capacidade de comunicar-se eficazmente. Identificando o professor como "o problema" da Educação brasileira, Dellanoy e Sedlacek (2000) arrolam justificativas para reformar a Educação por meio de políticas que afetem diretamente os docentes, tais como certificação e recertificação, novos Planos de Carreira, avaliação e remuneração por desempenho, entre outras.

A certificação docente é definida, no relatório, como um processo necessário para atestar que um professor está apto a ensinar. Os autores defendem que o Brasil deveria limitar o ingresso na carreira aos professores certificados, como forma de recrutar

\footnotetext{
${ }^{2}$ A "nova gestão pública" se apoia na gestão por resultados. Enfatiza princípios como eficiência, eficácia, qualidade nos serviços prestados, desempenho, orientação para resultados, responsabilização e flexibilidade. (REZENDE, 2002). Entre os efeitos de sua implementação está a instauração de uma política de remuneração variável para os trabalhadores - variável de acordo com o desempenho e/ou comprovação de competências -, o que tende a levar à extinção da isonomia salarial e ampliar as divisões na classe trabalhadora, ao estimular em seu interior a competição individual/grupal pelo melhor desempenho e respectivo bônus salarial. Nesse modelo, o Estado elimina gradualmente a sua responsabilidade pelo aumento salarial do conjunto dos trabalhadores, seguindo a lógica neoliberal de racionalização dos gastos públicos. (GENTILI, et al., 2004). Ao mesmo tempo, transfere essa responsabilidade para cada trabalhador, que passa a disputar com outros as gratificações reservadas para premiar os melhores desempenhos.
} 
os melhores candidatos à docência. (DELLANOY; SEDLACEK, 2000). Nesses termos, a certificação constituiria uma barreira à entrada no mercado de trabalho docente, o que poderia, contraditoriamente, provocar o efeito indesejado pelo Banco Mundial de afastar candidatos promissores da profissão docente.

As recomendações dos autores - de avaliação, certificação e recertificação dos professores - são atreladas a outra estratégia considerada importante pelo BM, qual seja: a de vincular os aumentos salariais ao desempenho do docente. A diferenciação de aumentos salariais para os professores contribuiria para sustentar financeiramente o sistema educacional. (DELLANOY; SEDLACEK, 2000). Segundo os autores, a iminência de crise no financiamento da Educação impede a melhoria dos salários de todos os professores, uma vez que esses constituem uma das maiores categorias de trabalhadores do setor público. Por isso, recomendam a reformulação dos Planos de Carreira de estados e municípios de modo que vinculem a progressão salarial do professor ao seu desempenho em avaliações docentes. (DELLANOY; SEDLACEK, 2000). A seguir, apresentamos os instrumentos jurídico-normativos, cujos propositores tentam desde 2003 implantar exames para docentes e candidatos à docência no Brasil. A finalidade das propostas coaduna com as recomendações do BM quanto ao uso dos resultados das avaliações docentes.

\section{Exames para professores e candidatos à docência}

No Brasil, a proposta de criação de um sistema federativo de certificação de competências de professores desponta com o Parecer CNE/CP $n^{\circ}$ 009/2001, que trata das Diretrizes Curriculares Nacionais para a Formação de Professores da Educação Básica. (BRASIL, 2001). Em 2002, a proposta é reiterada na Resolução CNE/CP $n^{\circ} 1$. (BRASIL, 2002). Em 2003, torna-se tema do Projeto de Lei $(\mathrm{PL}) \mathrm{n}^{\circ} 1.172$, de autoria de Raquel Teixeira (PSDB-GO), que dispõe sobre as diretrizes da política nacional de formação, certificação e valorização do magistério público. (BRASIL, 2003a). Ainda em 2003, o então ministro da Educação Cristovam Buarque publica a Portaria $n^{\circ} 1.403$ visando instituir um "Sistema Nacional de Certificação e Formação Continuada de Professores", composto, entre outros elementos, por um Exame Nacional. (BRASIL, 2003b). Conhecido como "Provão do Professor", o exame avaliaria conhecimentos e competências de professores e concluintes com o objetivo principal de servir como instrumento para avaliar os cursos de formação de professores. (BRASIL, 2003b).
O "Certificado Nacional de Proficiência Docente", que seria concedido aos aprovados, não seria pré-requisito para o ingresso na carreira ou para promoção salarial dos professores. (BRASIL, 2003b). Esse Exame de Certificação previa a criação de instrumentos de avaliação com base em matrizes de conhecimentos, competências e habilidades. Essas matrizes, segundo o Ministério da Educação (MEC), foram estabelecidas de forma coletiva, participativa e democrática por "mais de 7 mil profissionais da Educação", em 27 encontros estaduais e um encontro nacional, ocorridos em agosto e setembro de 2003, respectivamente. (BRASIL, 2003c, p. 9).

O primeiro e único encontro nacional, elaborado por iniciativa da antiga Secretaria de Educação Infantil e Fundamental do MEC, "contou com a participação de 800 delegados eleitos nos encontros estaduais e mais de cem convidados" (BRASIL, 2003c, p. 9). Segundo Freitas (2003a, p. 2), o I Encontro Nacional do Sistema de Formação Continuada e Certificação de Professores revelou a "centralização e autoritarismo do MEC, já indicada em vários dos encontros estaduais, para aprovar, a qualquer custo, as referidas matrizes, de modo a garantir a anuência dos educadores ao conteúdo do Exame de Certificação". (FREITAS, 2003a, p. 2). A proposta enfrentou, naquele momento, a crítica e a resistência manifesta de professores e entidades, entre os quais se destacou a professora Helena de Freitas, na época presidente da Associação Nacional pela Formação dos Profissionais da Educação (ANFOPE), e o Fórum Nacional em Defesa da Escola Pública (FNDEP).

As principais críticas traçadas por Freitas e pelo FNDEP referem-se às implicações da execução da proposta de certificação, que desconsiderava elementos de contexto apontados por estudiosos da área, e ao processo centralizado de elaboração e encaminhamento da mesma. (FREITAS, 1999, 2001, 2002, 2003a, 2003b, 2004, 2007; FNDEP, 2003). O Exame de Certificação, previsto para ter início no primeiro semestre de 2004, foi adiado para o segundo, não chegando a ser realizado. Segundo o Sindicato de Professores de São Paulo (SINPRO-SP, 2003), tal adiamento foi uma vitória fruto da pressão e crítica dos profissionais e entidades.

Embora amplamente rechaçada por professores, representantes de associações e universidades, a Portaria $n^{\circ} 1.403 / 2003$ encontrava respaldo legal na Resolução CNE/CP no 1/2002, que previa a criação de um sistema federativo de certificação de competência dos professores de Educação Básica. (BRASIL, 2002). Mesmo assim, essa Portaria foi revogada pelo MEC em maio de 2004. (BRASIL, 2009c).

Em 2007, nova tentativa de criação de um Exame Nacional de Certificação foi lançada pelo 
deputado Gastão Vieira (PSDB/MA) com o Projeto de Lei $(P L) n^{\circ} 1.088$, que pretendia alterar a Lei de Diretrizes e Bases da Educação Nacional (LDBEN) para instituir o Exame Nacional de Certificação como um pré-requisito para o exercício da docência na Educação Básica. (BRASIL, 2007a). Segundo Gastão Vieira, tratava-se de "estabelecer uma porta de entrada [...] um elemento adicional importante aos meios de recrutamento e seleção hoje existentes, em especial os concursos públicos". (BRASIL, 2007a, p. 2-3). Para o autor do PL, o Exame estabeleceria "um marco de padrão de qualidade para ingresso na carreira" e induziria "positivamente à melhoria da qualidade dos cursos de formação inicial". (BRASIL, 2007a, p. 3). Com relação ao público-alvo, o texto desse PL explicita que o Exame avaliaria conhecimentos, habilidades e competências de candidatos à carreira docente e diplomados após a data de possível vigência da Lei, não sendo, portanto, retroativo aos professores já em exercício e aos diplomados antes dessa data. (BRASIL, 2007a).

Ainda em 2007, o senador Wilson Matos (PSDB/PR) propôs, por meio do Projeto de Lei do Senado (PLS) no 403, a criação do "Exame Nacional de Avaliação do Magistério da Educação Básica" - ENAMEB. (BRASIL, 2007b). A senadora Rosalba Ciarlini (DEM/RN), relatora desse PLS na Comissão de Educação, Cultura e Esporte do Senado Federal, comenta: "No mais, parece-nos, se não incompreensível, no mínimo contraditório que um profissional acostumado, por dever de ofício, a avaliar não seja avaliado". (BRASIL, 2009c, p. 2). Citando a Portaria $n^{\circ} 1.403 / 2003$, a senadora afirma que o ENAMEB não constitui propriamente uma novidade. (BRASIL, 2009c). Considera a proposta oportuna e apresenta emendas para que o ENAMEB seja estendido ao setor privado e deixe "a critério dos sistemas de ensino a possibilidade de utilizar os resultados do Exame como parte de programas de avaliação de desempenho para fins remuneratórios e de progressão na carreira docente". (BRASIL, 2009c, p. 4).

O ENAMEB avaliaria o desempenho, habilidades e competências apenas dos docentes no exercício efetivo do magistério (BRASIL, 2007b), não contemplando os aposentados e candidatos à profissão. No texto original, o autor do PLS indica que os dados obtidos mediariam a elaboração de metas para o aperfeiçoamento e reciclagem dos docentes visando a superação das dificuldades enfrentadas por eles em sala de aula. (BRASIL, 2007b). Não fica totalmente claro se o ENAMEB seria um instrumento de avaliação teórica ou prática do professor, ou seja, se avaliaria conhecimentos ou de fato desempenho em sala de aula. Ao justificar que ele permitiria "verificar as dificuldades enfrentadas pelos professores na sala de aula", o autor do PLS no 403/2007 sugere se tratar de efetiva avaliação de desempenho. (BRASIL, 2007b, p. 2). Entretanto, uma das emen- das incorporadas ao texto do PLS acrescenta que o ENAMEB seria constituído de provas com uma parte geral e outra específica. (BRASIL, 2009c).

O PLS no 403 foi aprovado na Comissão de Educação, Cultura e Esporte do Senado Federal com emendas, em caráter terminativo, sendo remetido à Câmara dos Deputados em 25/09/2009, quando é apresentado como PLS no 6.114/2009. (BRASIL, 2009a). Em outubro de 2009, a Mesa Diretora da Câmara dos Deputados solicita a apensação do PL $\mathrm{n}^{\circ} 1.088 / 2007$ a esse novo PLS, indicando suposta correlação entre as matérias. (BRASIL, 2009d). Em junho de 2010, Gastão Vieira requisita a desapensação do PL n 1.088 do PLS n ${ }^{0} 6.114$, argumentando que não havia correlação apropriada entre as matérias. (BRASIL, 2010a). O deputado alega que o primeiro alteraria a LDBEN para instituir o Exame de Certificação como "condicionalidade" para o exercício da docência, enquanto o segundo visava disponibilizar os resultados do ENAMEB aos sistemas de ensino para que esses os utilizassem "como parte integrante de programas de avaliação de desempenho e para fins de progressão na carreira do magistério". (BRASIL, 2010a, p. 1). O requerimento do deputado é indeferido. (BRASIL, 2009d).

O deputado Antônio Carlos Biffi (PT/MS) foi designado relator do PLS $n^{\circ}$ 6.114/2009. (BRASIL, 2009d). Ele entende que "é chegada a ora (sic) de instituir por lei federal um sistema de avaliação docente como proposto nos dois projetos em apreciação [PLS no 6.114/2009 e PL no 1.088/2007]". (BRASIL, 2010e, p. 5). O relator, de parecer favorável ao PLS, elabora um Substitutivo sugerindo que:

- o ENAMEB possa ser prestado por professores e candidatos à docência;

- os resultados possam ser utilizados também para ingresso na carreira;

- o objetivo do ENAMEB de "avaliar o desempenho" seja substituído pelo de "avaliar os conhecimentos". Para o relator, a aplicação de provas constitui avaliação de conhecimentos e não avaliação de desempenho que, em sua análise, pressuporia "observação em sala de aula, análise de material produzido pelo docente para ministrar suas aulas, produção de portfólio etc.". (BRASIL, 2010e, p. 6) e

- seja incorporada ao inciso IV do art. 67 da LDB, a sugestão do PL $n^{\circ} 1.088 / 2007$ de acrescentar a avaliação de conhecimentos entre os fatores de progressão funcional na carreira (BRASIL, 2010e), que atualmente contemplam a titulação/habilitação e a avaliação de desempenho.

Embora o relator tenha fundido o $\mathrm{PL} \mathrm{n}^{\circ}$ $1.088 / 2007$ e o PLS no 6.114/2009 no Parecer exarado, a ideia central do primeiro $\mathrm{PL}$ - de 
instituição de um Exame Nacional de Certificação como pré-requisito para o exercício da docência não foi incorporada ao texto final do Substitutivo. A "condicionalidade" chocava-se com o "caráter voluntário" do ENAMEB. De acordo com o relator deputado Antônio Carlos Biffi (PT/MS),

[...] ao optar pela participação voluntária no [ENAMEB], decidimos pela não incorporação ao Substitutivo [...] de um exame nacional de certificação como pré-requisito para o exercício do magistério na educação básica [...] É nosso entendimento que a certificação como condição obrigatória para acesso à atividade profissional do magistério seria uma barreira interposta entre a habilitação ou titulação acadêmica e o concurso público, pois esse exame obrigatório não substituiria o processo de seleção sob responsabilidade de cada ente federado no País. Portanto, entendemos que deve ser incumbência da União assegurar qualidade aos cursos de formação inicial [...] (BRASIL, 2010e, p. 8-9, grifos do autor).

Assim, outra tentativa de implantar no Brasil um Exame Nacional de Certificação parece ter sido freada, dessa vez, pelos embates travados entre partidos e no interior do Governo.

O Substitutivo não explicita, como o texto do PLS no 403/2007, o objetivo de avaliar o desempenho dos docentes, mas sim o de aferir conhecimentos, habilidades e competências de docentes em exercício efetivo, de habilitados para a docência e de candidatos ao ingresso nessa carreira. (BRASIL, 2010e). Então, o PLS nº 6.114/2009 também pretende ampliar o foco do ENAMEB. Além disso, demarca que o Exame será constituído de provas com uma parte geral e outra específica e seus resultados poderão ser utilizados pelos entes federados para fins de seleção de professores, como parte de programas de avaliação de conhecimentos ou de progressão na carreira. (BRASIL, 2010e).

Apesar de não incorporar a ideia central do PL no $1.088 / 2007$, o Substitutivo propõe que a contratação de professores por parte das Secretarias de Educação a partir do uso dos resultados do ENAMEB possa se dar em caráter temporário ou emergencial. (BRASIL, 2010e). Trata-se de um reconhecimento formal da falta de professores nos sistemas de Educação do país, bem como de condições objetivas de trabalho e formação para esses docentes. O PLS n ${ }^{0}$ $6.114 / 2009$, nesse sentido, pode contribuir para a institucionalização desse quadro de precarização do trabalho docente na Educação Básica brasileira.

Em 28 de maio de 2009, portanto, durante o processo de tramitação do PLS no 6.114/2009 (ENAMEB), o ministro da Educação Fernando Haddad publica a Portaria Normativa $n^{\circ} 6$, que institui o "Exame Nacional de Admissão de Docentes". (BRASIL, 2009b). A finalidade apresentada foi a de "disponibilizar parâmetros nacionais para a realização de concursos para contratação de docentes para a educação básica no âmbito dos Estados, do Distrito Federal e dos Municípios". (BRASIL, 2009b, p. 1). Essa Portaria tinha como objetivos "conferir parâmetros para autoavaliação dos futuros docentes, com vistas à continuidade da formação e à inserção no mundo do trabalho", "contribuir para a melhoria do desempenho profissional de futuros docentes", "avaliar a compatibilidade entre o perfil do docente e as diretrizes curriculares nacionais [DCN] dos cursos de licenciatura e pedagogia", entre outros. (BRASIL, 2009b, p. 1). O Exame de Admissão avaliaria "competências e habilidades imprescindíveis à vida docente, ao mundo do trabalho e ao exercício da cidadania, tendo como base [uma] matriz de competências". (BRASIL, 2009b, p. 2). A participação no Exame seria voluntária e "circunscrita aos egressos do ensino superior", indicando a intenção do MEC de avaliar os cursos de formação de professores, conforme objetivo citado acima. (BRASIL, 2009b, p. 2). Um ano após a publicação da Portaria Normativa $\mathrm{n}^{0}$ 6, o ministro Fernando Haddad lança a Portaria Normativa $n^{\circ} 14$, por meio da qual institui o "Exame Nacional de Ingresso na Carreira Docente". (BRASIL, 2010c). Esclarece o ministro que a nova Portaria constitui apenas uma atualização da Portaria nº 6. (BRASIL, 2010b).

A Portaria $n^{\circ} 14 / 2010$ tem a mesma finalidade da Portaria n 6/2009, no entanto, apresenta um diferencial, visa a

[...] oferecer um diagnóstico dos conhecimentos, competências e habilidades dos futuros professores para subsidiar as políticas públicas de formação continuada [e] construir um indicador qualitativo que possa ser incorporado à avaliação de políticas públicas de formação inicial. (BRASIL, 2010c, p. 11).

Ambas as Portarias estabelecem que o uso dos resultados dos exames pelos entes federados está condicionado à formalização de adesão por parte desses ao INEP. (BRASIL, 2009b, 2010c). A Portaria $n^{\circ} 14 / 2010$, porém, especifica que fica a critério de cada Secretaria de Educação definir como utilizará os resultados do Exame de Ingresso (BRASIL, 2010c). Embora não limite a realização do Exame aos egressos do Ensino Superior, como a Portaria $n^{\circ}$ 6/2009, a Portaria n 14/2010 não explicita o seu público-alvo. Esse esclarecimento aparece somente nos "Referenciais" do Exame, expostos para consulta pública, onde se lê que: "o Exame será destinado a todos que tenham concluído ou estejam concluindo cursos de formação inicial para a docência, e que desejam ingressar na carreira do magistério". (BRASIL, 2010d, p. 4). Assim, a Portaria no 14/2010 não mais restringe a participação no Exame aos egressos do Ensino Superior. Contudo, quando afirma que pretende fazer dos Referenciais padrões docentes - que definiriam o perfil do professor desejado -, o MEC sinaliza que eles não serviriam apenas como 
base para a construção do Exame Nacional de Ingresso, mas também "como um marco para orientar as políticas de seleção, formação, avaliação e desenvolvimento na carreira do magistério". (BRASIL, 2010d, p. 2). Padrões docentes, desse modo, constituiriam parâmetros para avaliar a adequação dos conhecimentos, habilidades e competências do professor desde a sua formação até a aposentadoria.

Por fim, embora não se refira diretamente à criação de um instrumento de avaliação dos professores, mas a ela se vincule, cabe destacar o PLS $n^{\circ}$ 319/2008, de autoria do senador Cristovam Buarque (PT), que "cria o décimo-quarto salário dos profissionais da educação da rede pública". (BRASIL, 2008, p. 1). Esse PLS está em decisão terminativa na Comissão de Assuntos Sociais do Senado Federal, tendo já sido aprovado nas Comissões de Educação, Cultura e Esporte e de Assuntos Econômicos.

O senador justifica a criação do $14^{\circ}$ salário na Educação Pública com base na "literatura empresarial", que apresenta "vários exemplos positivos de que o incentivo salarial é um eficiente estimulador da produção". (BRASIL, 2008, p. 2). Cita Pernambuco e Minas Gerais como estados que adotaram "uma bonificação por produtividade dos profissionais da Educação Básica", mas não apresenta dados que comprovem melhoria da qualidade da Educação vinculada a essa bonificação. (BRASIL, 2008, p. 2). Em suma, o PLS constitui um incentivo econômico aos profissionais da Educação para que elevem a produtividade e o Ideb de suas escolas em $50 \%$ no ano escolar. (BRASIL, 2008). ${ }^{3}$ O PLS, afirma o senador, seria uma "pequena contribuição para inserirmos os profissionais da educação como a peça principal para o sucesso da educação básica". (BRASIL, 2008, p. 2, sem grifos no original).

Cristovam Buarque transfere a relação incentivo salarial-produtividade do campo empresarial diretamente para o setor público de Educação, acreditando que "somente com a satisfação financeira dos educadores", entendidos por ele como "peça principal da educação", é possível "tornar mais eficazes as escolas" e, assim, "dar o salto de qualidade que [o Brasil] precisa para ingressar no seleto grupo de países que priorizam a educação e são aclamados como desenvolvidos". (BRASIL, 2008, p. 2).

Nos termos colocados pelo PLS no 319/2008, a elevação do Ideb em $50 \%$, ou a um índice superior a 7.0 - o que representaria uma revolução, se considerados os Ideb e as condições dos sistemas de ensino atuais - poderia ser alcançada se os trabalhadores da Educação recebessem um empurrão salarial. É importante observar que o estímulo real (14º salário) somente será concedido após atingirem

\footnotetext{
${ }^{3}$ O PLS estabelece que as escolas que atingirem Ideb "igual ou superior a sete $(7,0)$ farão jus automaticamente ao décimo-quarto salário". (BRASIL, 2008, p. 1).
}

a meta estipulada. Professores e demais trabalhadores da Educação certamente dobrarão esforços para receber o $14^{\circ}$ salário, mas talvez não alcancem a meta, embora venham a intensificar o seu trabalho.

A nova proposta de Cristovam Buarque tende a instituir nacionalmente uma política já desenvolvida no estado de São Paulo pelo governo do PSDB, qual seja: a gratificação por resultados ou remuneração por desempenho às escolas ou equipes escolares que elevam seus indicadores educacionais. (IG, 2009). Essa política de prêmios, em São Paulo, pretende recompensar apenas $20 \%$ da categoria, o que, aliás, para ser anualmente efetivado, dependerá da dotação orçamentária do estado. (IG, 2009). $\mathrm{Na}$ Colômbia, apenas $0,8 \%$ dos professores foram premiados quando essa política foi implementada em meados de 1990. (HERRÁN; SALAZAR, 2004).

Esses são os principais documentos nacionais que propõem alguma forma de avaliação e bonificação ao professor, alegando necessidade de se melhorar a qualidade da Educação. Como foi possível verificar, parte deles tramitou e ainda tramita simultaneamente, embora seus objetivos, públicoalvo e utilização dos resultados não sejam exatamente os mesmos. No próximo tópico discutiremos pormenorizadamente o Exame Nacional de Ingresso na Carreira Docente, ${ }^{4}$ cuja primeira versão está prevista para ser realizada em 2011 para os candidatos interessados em trabalhar na Educação Infantil e séries iniciais do Ensino Fundamental. (AGÊNCIA BRASIL, 2010).

\section{O Exame Nacional de Ingresso na Carreira Docente}

A análise dos Referenciais do Exame Nacional de Ingresso indica que, com a centralização do planejamento e da operacionalização do Exame pelo INEP, o MEC espera atrair e selecionar bem os futuros professores da Educação Básica. (BRASIL, 2010d). De acordo com os Referenciais,

[...] para garantir bons professores em cada sala de aula, é preciso atrair candidatos com grande potencial para alcançar [o] perfil desejado para a docência, para que então se possa selecionar os melhores candidatos. (BRASIL, 2010d, p. 3).

O modelo deverá funcionar tal qual o Exame Nacional do Ensino Médio: os professores farão o Exame e as secretarias de Educação poderão utilizar os resultados para selecionar os profissionais que contratarão. (AGÊNCIA BRASIL, 2010). Igual-

\footnotetext{
${ }^{4}$ Após a publicação da Portaria no 3/2011 (BRASIL, 2011a), o Exame Nacional de Ingresso passou a se chamar "Prova Nacional de Concurso" e sua primeira versão está prevista para 2012, uma vez que as matrizes de referência da prova ainda estão sendo elaboradas. (CNTE, 2011)
} 
mente, os professores poderão escolher as cidades ou redes em que pretendem trabalhar. A atratividade, no entanto, conforme destacado pela Confederação Nacional dos Trabalhadores em Educação (CNTE, 2010b), dependerá das ofertas de emprego público, quando os entes federados com os menores salários e/ou precárias condições de trabalho deverão encontrar dificuldades para atrair os professores melhor classificados no cadastro nacional do MEC. Cidades, estados e regiões mais ricas, que a priori pagariam melhores salários e ofereceriam maiores benefícios aos professores, certamente terão vantagem na competição pelos "melhores resultados" do cadastro nacional. Mas como o MEC ou INEP regulará essa competição? Que entes ou sistemas terão prioridade na captação dos docentes com "melhores resultados"? Ou ficará a critério dos professores decidirem para onde migrarão?

A Organização para Cooperação e Desenvolvimento Econômicos (OCDE, 2006) considera a mobilidade positiva tanto para professores quanto para escolas, pois tende a diversificar a experiência do professor e a difundir novas ideias e abordagens nas escolas. A mobilidade também possibilitaria que professores "eficazes" circulassem em diferentes meios. Além disso, a OCDE (2006) recomenda a negociação direta e individual entre professor e escola (recrutamento aberto), no sentido de que a escola possa escolher seus professores e vice-versa. Essa aproximação, segundo a OCDE (2006), criaria no professor o senso de comprometimento com a escola necessário para realizar um trabalho eficaz. Em contrapartida, excluiria os sindicatos da mesa de negociação.

O ministro Fernando Haddad acredita que o Exame Nacional de Ingresso "pode ajudar a melhorar as condições salariais dos professores da rede pública". (AGÊNCIA BRASIL, 2010, p. 1). Segundo o ministro,

[...] o objetivo é aumentar o salário do professor, porque o professor bem formado vai ser disputado. Todo mundo quer atrair para sua rede os professores que tenham condição de mudar a realidade da escola pública do Brasil. Todo o projeto visa à valorização da carreira. (AGÊNCIA BRASIL, 2010, p. 1).

Nesse sentido, o Exame de Ingresso do MEC poderá implicar a negociação salarial direta entre professor e secretarias de Educação, uma vez que essas podem utilizar o Exame de forma livre, escoIhendo e captando os "melhores resultados", independentemente de seu portador e do local de origem desse. Igualmente, os professores podem escolher as melhores propostas salariais. Assim, é possível que essas se flexibilizem e os salários sejam diferenciados conforme a posição do candidato no ranking de classificação. A valorização dos professores, então, anunciada pelo MEC com a realização periódica do Exame, pode vir a depender prioritariamente de seu desempenho. Embora o Exame seja dirigido a pessoas que queiram ingressar nas redes públicas de ensino, professores em efetivo exercício, insatisfeitos com a remuneração percebida, podem realizálo para disputar melhores salários em outras redes ou entes federados. (AGÊNCIA BRASIL, 2010). Conforme o ministro Fernando Haddad, "o objetivo do projeto é ampliar o horizonte do profissional". (AGÊNCIA BRASIL, 2010, p. 1).

Os Referenciais do Exame Nacional de Ingresso apresentam um conjunto de 20 fatores que compõem o perfil do docente desejado pelo MEC. Uma rápida comparação com a Matriz de Referência do Exame de Certificação proposto pelo ex-ministro Cristovam Buarque, em 2003 (BRASIL, 2003b), evidencia o caráter instrumental, técnico e altamente orientado por resultados da matriz atual, posta à consulta pública no website do INEP de 19/05 a 03/07/2010. (AGÊNCIA ESTADO, 2010). As entidades que em 2010 questionaram o Exame de Ingresso afirmam que os Referenciais "não contemplam dimensões importantes a serem consideradas no trabalho docente, especialmente aquelas voltadas para uma formação humanista". (BRASIL, 2010b, p. 2).

O MEC cita as conclusões de um estudo da Organização para Cooperação e Desenvolvimento Econômicos - OCDE (2006), intitulado "Professores são importantes: atraindo, retendo e desenvolvendo professores eficazes", para justificar perante os leitores dos Referenciais, durante a consulta pública, a necessidade de o Brasil "definir de forma clara e concisa o que se espera em relação aos conhecimentos e habilidades dos professores, ou seja, definir padrões para um bom professor". (BRASIL, 2010d, p. 1). Conforme mencionamos, a ideia de criar padrões docentes é proporcionar "um marco para orientar as políticas de seleção, formação, avaliação e desenvolvimento na carreira do magistério". (BRASIL, 2010d, p. 1).

A proposta dos Referenciais é construir, via consulta pública, padrões docentes nacionais para, num primeiro momento, fundamentar a realização do Exame de Ingresso. (BRASIL, 2010d). Esses padrões delinearão o perfil docente que os candidatos à carreira deverão comprovar no Exame. Posteriormente, caso os padrões venham a se tornar efetivos, o MEC tenderá a utilizá-los para orientar a formação inicial e continuada de professores e os processos de avaliação docente. A OCDE (2006), no documento citado nos Referenciais, afirma inúmeras vezes que "é importante que o processo seletivo seja baseado em padrões claros, [concisos] transparentes e amplamente aceitos [consentidos] com relação ao que iniciantes devem saber e ser capazes de fazer para que sua prática seja eficaz". (OCDE, 2006, p. 175). 
O MEC (BRASIL, 2010d , p. 6) explicita que os 20 fatores que compõem o perfil do professor almejado nos Referenciais foram levantados a partir de "fatores comuns ao perfil de um bom professor em diversos países" (Austrália, Canadá, Chile, Cingapura, Cuba, EUA e Inglaterra), escolhidos por possuírem "definições claras e compartilhadas sobre os critérios do que seria um bom professor"; por utilizarem "esses critérios para avaliação em algum momento da carreira" e por terem "bom desempenho em exames padronizados como o PISA". Os fatores referem-se somente àqueles identificados como passíveis de serem medidos pelo Exame de Ingresso, que será constituído por uma prova escrita. (BRASIL, 2010d). Foram, portanto, excluídos do perfil desejado os aspectos que, apesar de sua importância - como reconhece o MEC -, somente poderiam ser verificados "por meio da prática docente, em sala de aula", ou seja, por avaliação de desempenho ou certificação de competências. (BRASIL, 2010d, p. 6).

Estabelecer um perfil docente a partir de um modelo "internacional" de "bom professor" - construído com base na recorrência de padrões docentes comuns nos países de PISA elevado e outros - não pode concorrer para a melhoria da qualidade da Educação Básica no Brasil, pois de que modo o professor considerado eficaz em um local ou país específico pode se tornar referência internacional para a superação dos problemas educacionais de outros contextos muito distintos? Entretanto, o MEC define o perfil docente nos Referenciais do Exame de Ingresso a partir de referências externas. O eixo do perfil docente foi importado de países que obtiveram bons resultados educacionais no PISA 2006 e possuem claros padrões docentes utilizados na avaliação de professores. (BRASIL, 2010d). Então, a referência para definir o que constitui um bom professor não emerge da realidade sócio-histórica brasileira que condiciona nossas práticas e instituições sociais, mas das elaborações teóricas de organizações como a OCDE, voltada aos interesses de desenvolvimento econômico dos países centrais e não necessariamente aos das crianças, jovens e adultos da escola pública brasileira.

Com o Exame, o MEC pretende centralizar o processo de seleção de professores, enquanto mantém sua contratação e remuneração descentralizadas. Nesse processo, assumirá as funções de planejamento e operacionalização do Exame e estruturação do banco de dados sobre os resultados, enquanto aos entes federados caberá a sua aplicação. (BRASIL, 2010c). Embora o MEC acredite que a medida permitirá aumentar as contratações de professores por economizar recursos que seriam gastos com a realização de concursos públicos, não há garantias de que estados e municípios contratarão mais, uma vez que a folha de pagamento deverá continuar descentralizada e contingenciada pela Lei de Responsabilidade Fiscal.
Contrária a iniciativas como essa do MEC, a OCDE (2006) não recomenda centralizar processos de seleção e recrutamento de professores por considerar que os governos centrais desconhecem as necessidades locais das escolas. O recrutamento centralizado de professores a partir do Exame se constituiria em um processo impessoal, o que faria com que os professores selecionados não construíssem um senso de comprometimento com as escolas escolhidas por eles para o exercício do magistério. Considerando as escolas os agentes fundamentais da melhoria da aprendizagem dos alunos, a OCDE (2006) sugere que elas tenham autonomia efetiva em gestão de pessoal, isto é, que tenham liberdade para atrair, selecionar, recrutar, contratar, avaliar, demitir, desenvolver e até recompensar por desempenho seus professores.

\section{Questionamentos e críticas ao Exame $\mathrm{Na}$ - cional de Ingresso na Carreira Docente}

Em audiência realizada no dia 7 de junho de 2010, representantes da ANFOPE, da Associação Nacional de Política e Administração da Educação (ANPAE), da Associação Nacional de Pesquisa e Pós-Graduação em Educação (ANPEd), do Centro de Estudos Educação e Sociedade (CEDES) e do Fórum Nacional de Diretores de Faculdades/Centros/Departamentos e Educação das Universidades Públicas Brasileiras (FORUMDIR) entregaram carta ao ministro Fernando Haddad manifestando diversas preocupações acerca do Exame Nacional de Ingresso do MEC, entre as quais destacamos:

- avalia o professor sem antes definir e implantar um currículo base de formação;

- estabelecer uma matriz de referência para um exame dessa natureza, nesses termos, "contribuirá para um 'estreitamento da visão curricular da formação pela avaliação' dentro de um perspectiva homogeneizadora e de caráter fortemente 'conteudista' voltada para a 'operacionalização do saber-fazer'", ou seja, a matriz de referência vira o "currículo de formação" (BRASIL, 2010b, p. 2);

- poderá se caracterizar como mais um mecanismo de avaliação dos cursos de formação de professores;

- poderá conduzir a uma concepção de "educação por resultados" (BRASIL, 2010b, p. 2);

- poderá "remeter a uma perspectiva de avaliação docente já amplamente analisada e refutada pela área e que trabalhava na direção de introdução da 'certificação' como elemento estruturante na carreira do magistério" (BRASIL, 2010b, p. 2); 
- poderá gerar o ranqueamento dos professores e

- poderá estimular a produção e comercialização de materiais e cursinhos preparatórios. ${ }^{5}$ Assim, o Exame avaliará somente "o quanto os candidatos se prepararam para fazê-lo". (ANFOPE et al., 2010, p. 2).

Na ocasião, as entidades solicitaram a revogação da Portaria Normativa no 14/2010 e a suspensão da elaboração da matriz de referência "em razão das profundas implicações desse Exame para a educação brasileira". (ANFOPE et al., 2010, p. 2). Diante do exposto, o ministro esclareceu que "não há qualquer intenção no sentido da certificação ou avaliação de professores"; que o Exame "não pretende ter caráter de avaliação dos cursos de formação de professores", pois isso já é feito pelo ENADE e que ele "não pretende ser definidor dos currículos de formação de professores, pois essa definição já é feita por meio das DCN". (BRASIL, 2010b, p. 2).

Conforme Ata da Audiência, as discussões realizadas mostraram a urgência de se revogar o artigo 16 da Resolução CNE/CP 1/2002, que estabelece que o MEC

[...] coordenará e articulará em regime de colaboração [...] a formulação de proposta de diretrizes para a organização de um sistema federativo de certificação de competência dos professores de educação básica. (BRASIL, 2010b, p. 3).

A CNTE arrolou uma série de críticas e questões sobre a Portaria Normativa n 14/2010:

- o MEC não priorizou o debate para "definir a base conceitual e as melhores formas para implantação da proposta". A CNTE lamenta que a portaria não tenha sido discutida na $1^{\mathrm{a}}$ Conferência Nacional de Educação (CONAE) (CNTE, 2010b, p. 1);

- a portaria poderá abranger a avaliação dos docentes em exercício;

- ela não explicita que "a contratação, via cadastro nacional, destina-se a cargos públicos efetivos" (CNTE, 2010b, p. 1), podendo admitir contratações temporárias ou emergenciais, tal como proposto no PLS nº 6.114/2009 (ENAMEB);

- dispõe que o ingresso na carreira docente "requer dos entes federados a instituição de planos de carreira". Contudo, "os principais destinatários da proposta - municípios de menor porte - são os que menos possuem planos de carreira [docente]" (CNTE, 2010b, p. 1);

\footnotetext{
5 Ver APROVA CONCURSOS. Concurso Exame Nacional de Ingresso na Carreira Docente. 2010. Disponível em: <http://www. aprovaconcursos.com.br/concurso/exame-nacional-ingressocarreira-docente-enem-professores-/>. Acesso em: 12 fev. 2011.
}

- a existência de "um cadastro nacional de docentes aptos a serem contratados [...] não garante o preenchimento das vagas [...], especialmente em razão das condições de trabaIho, dos baixos salários e da falta de perspectiva na carreira". A portaria facilitará o acesso dos docentes à carreira desde que "se sintam atraídos pelas ofertas de empregos públicos" (CNTE, 2010b, p. 1) e

- embora preveja "o sigilo dos resultados individuais [...] a veiculação inapropriada de dados locais e regionais, através de universidades, pesquisadores ou Secretarias de Educação [...] sob a ótica do senso comum poderá induzir [à] perspectiva de ranking". (CNTE, 2010b, p. 1).

Para o Presidente da CNTE, Roberto Leão, é necessário "aprofundar o debate sobre as matrizes da prova e garantir que o Exame seja utilizado unicamente como ingresso dos docentes na carreira, nunca como avaliação dos professores". (CNTE, 2010a, p. 1). A CNTE, embora em visão preliminar tenha lamentado a falta de abertura do MEC ao diálogo e apontado vários questionamentos à Portaria, mostrou disposição para debater o assunto e solicitou "assento nas discussões sobre a regulamentação do Exame Nacional". (CNTE, 2010a, p. 1).

Na reunião realizada com o ministro Fernando Haddad, no dia 30 de junho de 2010, ficou deliberado que as entidades presentes (CNTE, Conselho Nacional de Secretários de Educação - CONSED e União dos Dirigentes Municipais de Educação UNDIME) iriam "compor um Comitê de Governança para avaliar o Exame Nacional e apresentar propostas para concretizar o projeto". (CNTE, 2010a, p. 1). ANFOPE, ANPEd, ANPAE, CEDES e FORUMDIR foram convidados a compor o Comitê desde que manifestassem disposição de debater propostas que contemplassem "as diferentes preocupações e perspectivas como as dos gestores dos sistemas de ensino, dos trabalhadores em educação e das instituições acadêmicas [de formação de professores]". (BRASIL, 2010b, p. 3).

Se, num primeiro momento, a ANFOPE e demais entidades solicitaram a revogação da Portaria Normativa $n^{0} 14 / 2010$, por entender que ela pode gerar profundas implicações para a Educação brasileira, posteriormente, acataram as proposições do ministro na audiência (07/06/2010) de encaminhar sugestões para o seu aprimoramento e de se juntar ao CONSED, UNDIME e CNTE para formular "uma proposta ainda mais consistente para o Exame [...] e suas respectivas 'matrizes de referência'". (MEC, 2010b, p. 3).

Governos e formuladores de políticas perceberam que a estratégia para implantar com mais sucesso suas reformas educacionais não é o 
enfrentamento direto com os sindicatos e entidades da classe docente, muito menos a imposição de políticas. O MEC, frente ao rechaço das entidades, inferiu que haveria resistência para a implantação do Exame Nacional de Ingresso e, inclusive, questionou o porquê das entidades se manifestarem tardiamente, quando o Exame ora proposto já havia sido instituído pela Portaria $n^{\circ}$ 6/2009. Rapidamente, o ministro abriu espaço para o diálogo com as entidades questionadoras, que exercem ampla influência na área educacional, e deliberou com elas que seriam "promovidas audiências públicas para que a categoria e a sociedade participem da discussão". (CNTE, 2010b, p. 1). Nesse contexto, teriam as entidades e os sindicatos, considerados obstáculos às reformas educacionais, se convertido em parceiros do Estado na formulação de políticas educacionais? Governos tentam envolver os sindicatos resistentes para não serem impeditivos das reformas. Desse modo, "não apenas o professor é objeto da política, mas também os sindicatos o são, posto que, individual ou sindicalmente pensado, o docente é apreendido como uma questão de Estado". (EVANGELISTA; SHIROMA, 2007, p. 537).

A instituição do Exame via Portaria e a centralização de seu planejamento, operacionalização e estruturação de banco de dados no INEP, com a descentralização de sua aplicação aos entes federados, mais uma vez evidenciam que o Estado centraliza as questões estratégicas e descentraliza as questões operacionais. (EVANGELISTA; SHIROMA, 2007). A estreita margem de "manobra" concedida às entidades, via participação no Comitê de Governança, não permite caracterizá-las como formuladoras da política. Os Referenciais pré-fabricados e postos à consulta pública são outra demonstração de que a participação não tem caráter deliberativo, mas apenas consultivo. A importação do eixo central do perfil docente também indica que não foram consideradas as necessidades reais da sociedade brasileira. No documento dos Referenciais, o MEC sugere que centralizar o processo de seleção de professores no INEP é condição para selecionar bem os professores, indicando com isso que os entes federados não têm expertise para realizar concursos públicos capazes de selecionar os professores desejados. (BRASIL, 2010d). Segundo o MEC,

[...] parece que o potencial dos concursos públicos não tem sido totalmente aproveitado, especialmente no que diz respeito aos conteúdos cobrados nas provas [...] pesquisa recente da Fundação Carlos Chagas constatou que os concursos públicos para professores de séries iniciais realizados no Brasil cobram, majoritariamente, conhecimentos ligados à legislação e à estrutura de funcionamento dos sistemas educacionais. Em relação aos conteúdos a serem ensinados, identificou-se que geralmente se cobra algum domínio da Língua Portuguesa, mas raramente de Matemática. Segundo a pes- quisa, existem poucas questões dos concursos referindo-se a fundamentos da educação, e menos questões ainda relacionando esses fundamentos às práticas docentes. Além disso, os itens seriam, em sua maioria, relativos a conteúdos teóricos, sendo abordados somente de modo superficial. (BRASIL, 2010d, p. 4).

Proposições de avaliação docente oriundas de diferentes partidos políticos - fundamentadas em distintas concepções de Educação, de avaliação, de formação, de prática pedagógica, de professor -, com os mais variados objetivos e finalidades, mostram que os posicionamentos sobre a matéria no âmbito do Governo e parlamentares andam pouco afinados.

De outro lado, a resistência de entidades, associações docentes, sindicatos, professores e universidades a exames de docentes parece ter se limitado às Portarias $n^{\circ} 1.403 / 2007$ e Normativa $n^{\circ}$ 14/2010. Enquanto a primeira foi rechaçada e revogada pela pressão daquelas instituições e dos pesquisadores, a segunda foi questionada sem ser, contudo, revogada. Os questionamentos foram incorporados pelo MEC para se chegar a um consenso com as entidades e, assim, viabilizar a implantação do Exame de Ingresso. Outras iniciativas, como o PLS, que cria o $14^{\circ}$ salário para os profissionais da Educação, são amplamente apoiadas pela população. Conforme enquete realizada pelo DataSenado, $98 \%$ dos votantes apoia a criação do $14^{\circ}$ salário, na crença de que se constitui em efetivo mecanismo de valorização e reconhecimento do trabalho do professor. (DATASENADO, 2011).

Apesar de capital e trabalho almejarem Educação de qualidade e entenderem que a avaliação do professor é um instrumento que pode contribuir para alcançá-la, as concepções de Educação e de avaliação docente defendidas por ambos se contrapõem no que se refere aos princípios, interesses e projetos sócio-históricos nos quais se sustentam. As políticas de avaliação docente produzidas nesse embate guardam as marcas da correlação de forças existente no âmbito do Estado.

\section{Considerações Finais}

O uso dos resultados dos exames e as justificativas para implantá-los evidenciam que para melhorar os indicadores educacionais governos pretendem investir na "peça principal da Educação": o professor. (BRASIL, 2008, p. 2). Esse investimento, na forma de incentivos econômicos por comprovada "produtividade", é recomendado pelos consultores das reformas tomando como referência "experiências bem-sucedidas" do meio empresarial. Não se pretende melhorar o ensino investindo no sistema educacional como um todo ou aprimorando as con- 
dições de trabalho docente, mas sim colocando o professor "à prova" por meio de avaliação de conhecimentos, de desempenho e/ou certificação e recertificação de competências. Não se trata de avaliar por formalidade, mas com a finalidade de condicionar ingresso, remuneração, progressão na carreira e estabilidade aos resultados obtidos nos exames.

A proposta de certificação docente enfrentou intensa resistência das entidades, associações docentes, universidades e pesquisadores em $2003 / 2004$, quando então pretendia praticamente servir de instrumento para avaliar os cursos de formação de professores. Entretanto, a resistência não intimida o Governo e os políticos a recolocarem-na periodicamente em pauta. Atualmente, a tentativa de implantação de exames para professores ou candidatos à docência em nível nacional corre por duas vias: pela Prova Nacional de Concurso e pelo ENAMEB. Os resultados de ambos podem ser utilizados pelos entes federados para contratação de professores, mesmo que em condição temporária ou emergencial.

Desde 2003, novos projetos de lei pretenderam instituir exames para docentes. Constatamos que parte desses projetos tramitou simultaneamente e, em alguns casos, enquanto matérias eram discutidas pelos parlamentares, o Governo atropelou o processo e emitiu portarias, instituindo os exames. Por que tanta prioridade às políticas de avaliação de docentes?

As políticas de avaliar professores e remunerá-los ou promovê-los na carreira segundo seu desempenho ou conhecimentos explicita a intenção de incutir, na Educação, a cultura da avaliação pautada na meritocracia, na competição entre pares, na responsabilização pelos resultados e na flexibilização salarial - elementos típicos do setor privado, mas cada vez mais presentes na totalidade do setor público. Esses elementos atendem aos interesses da nova gestão pública implantada na vaga neoliberal, na medida em que concorrem para a quebra da isonomia salarial e da solidariedade de classe entre os trabalhadores.

O professor da escola pública é, na sociedade de classes, um trabalhador formador das próximas gerações de trabalhadores. É formador de habilidades básicas, mas também de consciências, da capacidade de ler o mundo, de transformá-lo. A valorização do trabalhador docente é, nessa perspectiva, uma necessidade tanto do capital quanto do trabaIho, embora orientada por interesses antagônicos. Por seu potencial de reprodução e transformação, o professor é uma questão de Estado. (EVANGELISTA; SHIROMA, 2007).

A tentativa de atrelar incentivos financeiros ao desempenho e/ou conhecimentos do docente ou aos resultados de seus alunos em avaliações padronizadas instaura no campo educacional mais que uma cultura de avaliação, uma cultura de medição. Nesses termos, estabelece uma relação de dependência entre a avaliação de alunos e professores na medida em que melhor salário, condições de trabalho e satisfação do docente podem melhorar a qualidade do ensino e, por conseguinte, o desempenho discente. Da mesma forma, na lógica proposta, os resultados dos alunos nos testes servem de indicadores para avaliar o desempenho docente e condicionam seu salário, incentivos, gratificações, progressão funcional e até permanência no cargo. O bom aluno é apresentado como mero resultado/ efeito da boa atuação do professor que, por sua vez, se torna dependente dos alunos para manter seu patamar salarial. Esse círculo vicioso é um aspecto que fica obscurecido na cantilena dos benefícios da avaliação de desempenho docente. $O$ discurso da avaliação enfatiza apenas seu potencial de valorizar os bons professores, mas oculta seus efeitos deletérios como a competição, a precarização e a intensificação do trabalho, que redundam na desvalorização do docente.

As análises dos pressupostos das políticas em tela (hierarquização, exclusão, meritocracia) e seus efeitos (premiação, punição, competição, fragmentação da categoria, intensificação do trabalho, mobilidade da força de trabalho docente) tendem a indicar que as propostas de avaliação docente e de remuneração por desempenho miram o indivíduo e acertam o coletivo, atingindo diretamente a identidade e o movimento docente. A noção de categoria docente, de coletividade, fica ameaçada com a proposta de avaliação como estímulo à mobilidade de professores no território nacional. Frente à crise de sindicalização e de mobilização docente que enfrentam os sindicatos e considerando a possibilidade de negociação direta do professor com as secretarias de Educação, conseguirão eles a adesão dos "nômades eficazes"? Secretarias de Educação e sindicatos disputarão a "adesão" de professores à sua pauta de benefícios? Possivelmente ambos percam professores para as prometidas "vantagens da mobilidade".

A anunciada mobilidade da força de trabalho docente pretensamente resolveria o problema do desequilíbrio entre a oferta e a procura de professores em diferentes regiões do país. No entanto, também pode acarretar efeitos perversos para a categoria docente e seus sindicatos, como: estimular a concorrência entre os professores pelas melhores propostas econômicas e entre as secretarias de Educação pela contratação dos "melhores" candidatos; ampliar e fortalecer a negociação individual dos salários e das condições de trabalho; enfraquecer o papel coletivo, político e mediador dos sindicatos e ampliar a distância entre os professores e suas entidades e reivindicações políticas. Por isso, ao participar do aperfeiçoamento do Exame Nacional de Ingresso na 
Carreira Docente e de seus respectivos padrões docentes, as entidades, associações e sindicatos de professores caminham no fio da navalha.

Em março de 2011, o ministro Fernando Haddad divulgou nova Portaria sobre o Exame Nacional de Ingresso. Trata-se da Portaria Normativa $n^{\circ} 3$, de 2 de março de 2011, que institui a "Prova Nacional de Concurso para o Ingresso na Carreira Docente". (BRASIL, 2011a, p. 1). Pela segunda vez, se modifica o nome do Exame. As matrizes de referência da Prova Nacional, em discussão entre o MEC e as entidades apresentadas neste trabalho - e mais uma vez postas à consulta pública no website do INEP -, evidenciam a incorporação da "abordagem de avaliação de competências" (BRASIL, 2011b, p. 3) que, por sua vez, não expressa a concepção de Educação historicamente defendida pelas entidades e educadores comprometidos com o projeto histórico-social da classe trabalhadora. As entidades, associações e sindicatos que estão participando do aperfeiçoamento das matrizes de referência da Prova Nacional, como a CNTE, temiam que o Exame, tal como colocado pela Portaria $n^{\circ} 14 / 2010$, pudesse servir para avaliar o rendimento dos docentes das redes, criar rankings ou assumir o caráter de certificação. (CNTE, 2011). Mas em que medida a substituição de termos ou da forma do Exame expressa uma modificação de conteúdo, sentido e finalidades? A substituição de conceitos, no plano discursivo, pode ocultar a permanência da essência da política. Observamos que, uma vez envolvida no processo de aperfeiçoamento dessa política, a CNTE abrandou a sua postura inicial de questionamentos, colaborando com a discussão dos parâmetros da Prova Nacional com o MEC e demais entidades dentro do modelo de competências.

Melhorar indicadores e atingir metas não é uma questão técnica, mas, sobretudo, política. Está na agenda dos organismos multilaterais e dos empresários porque expressa a produção de uma Educação adequada aos propósitos e às demandas econômicas e políticas do capital, que, embora se constitua e atue politicamente, procura deslegitimar a luta política do trabalho, restringindo-a a uma mera luta por salários. Embora os sindicatos encontrem, atualmente, condições objetivas desfavoráveis à mobilização da categoria docente, os embates travados em torno das políticas de avaliação docente cujo caso emblemático de resistência encontramos em São Paulo, em 2010, liderado pelo Sindicato dos Professores do Ensino Oficial do Estado (APEOESP, 2010) - evidenciam as tensões e contradições. Embates dessa natureza fortalecem os movimentos de resistência e revelam a potencialidade dos sindicatos para frear reformas que visam a desvalorização e despolitização do professor, do ensino, da escola e de seu público, a classe trabalhadora.

\section{Referências}

AGÊNCIA BRASIL. Professores veem com preocupação exame nacional. CNTE Informa 533. 2 jun. 2010. Disponível em: <http://www.cnte.org.br/index. php?option=com_content\&task=view\&id=4241\&Itemid $=85>$. Acesso em: 3 jun. 2010.

AGÊNCIA ESTADO. MEC cria "Enem" para selecionar professores. 24 maio 2010. Disponível em: $\quad<$ http://noticias.br.msn.com/artigo.aspx?cpdocumentid=24346420 . . Acesso: 24 maio 2010.

ANFOPE et al. Carta de Manifestação entregue ao Ministro de Educação Fernando Haddad em Audiência com as Entidades. 7 jun. 2010. Disponível em: <http://anfope.spaceblog.com.br/834501/Cartade-Manifestacao-entregue-ao-Ministro-deEducacaoFernando-Haddad-em-Audiencia-com-as-Entidades>. Acesso em: 08 fev. 2011.

APEOESP. Sindicato dos Professores do Ensino Oficial do Estado de São Paulo. Fax Urgente, n. 38, mar. 2010. Disponível em: <http://apeoespsub.org.br/teste/ Fax/Fax_3810.pdf>. Acesso em: 02 abr. 2010.

APROVA CONCURSOS. Concurso Exame Nacional de Ingresso na Carreira Docente. 2010. Disponível em: <http://www.aprovaconcursos.com.br/concurso/ exame-nacional-ingresso-carreira-docente-enemprofessores->. Acesso em: 12 fev. 2011.

BARROSO, J. O Estado, a educação e a regulação das políticas públicas. Educação \& Sociedade, Campinas, v. 26 , n. 92 , p. $725-751$, out. 2005. DOI: $10.1590 /$ S0101-73302005000300002

BRASIL. Ministério da Educação. Conselho Nacional de Educação. Conselho Pleno. Parecer $n^{\circ}$ CNE/CP 009/2001. Diretrizes Curriculares Nacionais para a formação de professores da Educação Básica, em nível superior, curso de licenciatura, de graduação plena. Relatora: Raquel Figueiredo Alessandri Teixeira. Brasília, 8 maio 2001. Disponível em: <http://portal. mec.gov.br/cne/arquivos/pdf/009.pdf>. Acesso em: 29 abr. 2008.

Ministério da Educação. Conselho Nacional de Educação. Conselho Pleno. Resolução CNE/CP 1/2002. Institui Diretrizes Curriculares Nacionais para a formação de professores da Educação Básica, em nível superior, curso de licenciatura, de graduação plena. Brasília, 18 fev. 2002. Disponível em: <http://www. ourinhos.unesp.br/staa/docs/legislacao/resolucao_ cne_1.htm>. Acesso em: 4 mai. 2009.

Câmara dos Deputados. Comissão de Educação e Cultura. Raquel F. A. Teixeira. Projeto de Lei $\mathrm{n}^{\circ} \mathbf{1 . 1 7 2}$, de 2003. Dispõe sobre as diretrizes da política nacional de formação, certificação e valorização do magistério público. 2003a. Disponível em: <http:// www2.camara.gov.br>. Acesso em: 23 abr. 2008.

. Ministério da Educação. Gabinete do Ministro. Portaria no 1.403, de 9 de junho de 2003. Institui o Sistema Nacional de Certificação e Formação Continuada de Professores. Diário Oficial da União, Brasília, 10 
jun. 2003b. p. 50. Disponível em: <http://www.prolei. inep.gov.br>. Acesso em: 29 abr. 2008.

Ministério da Educação. Secretaria de Educação Infantil e Fundamental. Sistema nacional de Formação Continuada e Certificação de Professores. Matrizes de referência - anos iniciais do ensino fundamental. 2003c. Disponível em: <http://portal.mec. gov.br/seb/arquivos/pdf/Livreto.pdf>. Acesso em: 29 abr. 2008.

. Câmara dos Deputados. Comissão de Educação e Cultura. Gastão Vieira. Projeto de Lei $\mathbf{n}^{\circ} \mathbf{1 . 0 8 8}$, de 2007. Altera a Lei no 9.394, de 20 de dezembro de 1996, para instituir o exame nacional de certificação como pré-requisito para o exercício do magistério na educação básica e dá outras providências. 2007a. Disponível em: <http://www2.camara.gov.br>. Acesso em: 29 abr. 2008.

. Senado Federal. Wilson Matos. Projeto de Lei do Senado $n^{\circ}$ 403, de 10 de julho de 2007. Institui o Exame Nacional de Avaliação do Magistério da Educação Básica (ENAMEB). 2007b. Disponível em: <http:// legis.senado.gov.br/mate-pdf/10659.pdf>. Acesso em: 28 mar. 2010.

. Senado Federal. Cristovam Buarque. Projeto de Lei do Senado $n^{\circ}$ 319, de 20 de agosto de 2008. Cria o décimo-quarto salário dos profissionais da educação da rede pública e dá outras providências. 2008. Disponível em: <http://www.senado.gov.br/atividade/ materia/getTexto.asp?t $=13898 \& c=R T F \& t p=1>$. Acesso em: 6 fev. 2011.

Câmara dos Deputados. Wilson Matos. Projeto de Lei do Senado $n^{\circ} \mathbf{6 . 1 1 4}$, de 25 de setembro de 2009. Institui o exame nacional de avaliação do Magistério da Educação Básica - Enameb. 2009a. Disponível em: <http://www2.camara.gov.br>. Acesso em: 6 fev. 2011.

. Ministério da Educação. Conselho Nacional de Educação. Secretaria Executiva. Ministério da Educação. Portaria Normativa n 6, de 28 de maio de 2009. Institui o Exame Nacional de Admissão de Docentes. 2009b. Disponível em: <http://www.cmconsultoria.com. br/imagens/diretorios/diretorio14/arquiv01492. pdf $>$. Acesso em: 6 fev. 2011.

. Senado Federal. Comissão de Educação, Cultura e Esporte. Parecer sobre o Projeto de Lei do Senado $n^{\circ}$ 403, de 2007. Da Comissão de Educação, Cultura e Esporte, em decisão terminativa, sobre o Projeto de Lei do Senado no 403, de 2007, que institui o Exame Nacional de Avaliação do Magistério da Educação Básica (ENAMEB). Relatora: Rosalba Ciarlini. Brasília, 25 ago. 2009c. Disponível em: <http://legis.senado.gov.br/ mate-pdf/65228.pdf>. Acesso em: 28 mar. 2010.

. Câmara dos Deputados. Projeto de Lei e outras proposições. Proposição: PL-6114/2009. 2009d. Disponível em: <http://www.camara.gov.br/sileg/Prop_ Detalhe.asp?id=452755>. Acesso em: 12 fev. 2011.

Câmara dos Deputados. Gastão Vieira. Requerimento de Desapensação 7017, de 8 de junho de 2010. 2010a. Disponível em: <http://www.camara. gov.br/sileg/Mostrarlntegra.asp?CodTeor=777450>. Acesso em: 8 fev. 2011.

. Ministério da Educação. Ata de Audiência entre o Ministro da Educação e os representantes das Entidades de Estudos e Pesquisas em Educação. 7 jun. 2010b. Disponível em: <http://anfope.spaceblog. com.br/842363/Ata-de-Audiencia-entre-o-Ministro-daEducacao-e-os-representantes-das-Entidades>. Acesso em: 8 fev. 2011.

. Ministério da Educação. Gabinete do Ministro. Portaria Normativa no 14, de 21 de maio de 2010. Institui o Exame Nacional de ingresso na carreira docente. Diário Oficial da União, Brasília, Seção 1, n. 24, p. 11 , 24 maio 2010c. Disponível em: <http://noticias.cefet-rj. br/wp-content/uploads/2010/05/20100524-portaria_ normativa_mec.pdf>. Acesso em: 6 fev. 2011.

. Ministério da Educação. Instituto Nacional de Estudos e Pesquisas Educacionais Anísio Teixeira. Referenciais para o Exame Nacional de Ingresso na Carreira Docente. Documento para Consulta Pública. 2010d. Disponível em: <http://consultaexamedocente. inep.gov.br/publico/download/Referenciais_para_o_ Exame_Nacional_de_Ingresso_na_Carreira_Docente. pdf>. Acesso em: 6 fev. 2011

Senado Federal. Comissão de Educação e Cultura. Antonio Carlos Biffi. Parecer sobre o Projeto de Lei $n^{\circ}$ 6.114, de 2009, que institui o Exame Nacional de Avaliação do Magistério da Educação Básica - Enameb. 9 jun. 2010e. Disponível em: <http://www. camara.gov.br/sileg/Prop_Detalhe. asp?id=480893>. Acesso em: 6 fev. 2011.

. Ministério da Educação. Gabinete do Ministro. Portaria Normativa $n^{\circ} 3$, de 2 de março de 2011. Institui a Prova Nacional de Concurso para o Ingresso na Carreira Docente. Diário Oficial da União, Brasília, Seção 1, n. 44, p. 9, 03 mar. 2011a. Disponível em: <http:// www.audisa.net/arquivos/1299259781.pdf>. Acesso em: 20 mar. 2011.

Ministério da Educação. Instituto Nacional de Estudos e Pesquisas Educacionais Anísio Teixeira. Diretoria de Estudos Educacionais. Matriz de Referência da Prova Nacional de Concurso para o Ingresso na Carreira Docente. Educação Infantil e Anos Iniciais do Ensino Fundamental. Proposta Inicial para Análise e Discussão. 2011b. Disponível em:<http://portal.mec. gov.br/index.php?option=com_docman\&task=doc_ download\&gid=7626\&ltemid $>$. Acesso em: 20 mar. 2011.

CNTE. Confederação Nacional dos Trabalhadores em Educação. Concurso Nacional de Professores: CNTE quer ampliação de debate. CNTE Informa 538. 7 jul. 2010a. Disponível em: <http://www.cnte.org.br/ index.php?option=com_content\&task=view\&id=4444\&l temid=85>. Acesso em: 12 ago. 2010.

Exame Nacional de ingresso na carreira docente: visão preliminar da CNTE. CNTE Informa 532. 26 maio 2010b. Disponível em: <http://www.cnte. org.br/index.php? option=com_content\&task=view\&id= 4159\&Itemid=85>. Acesso em: 26 maio 2010. 
A voz da educação. Programa 156: ingresso na carreira pública poderá ser feita pela nova Prova Nacional. 14 mar. 2011. Disponível em: <http://www. cnte.org.br/index.php?option=com_content\&task=view \&id=6425\&Itemid=208>. Acesso em: 17 mar. 2011.

DATASENADO. Enquete: 98\% dos internautas apóiam $14^{\circ}$ salário para professores. 17 jan. 2011. Disponível em: <http://www.senado.gov.br/noticias/opiniaopublica/ noticia.asp?not=40>. Acesso em: 13 fev. 2011.

DELANNOY, F.; SEDLACEK, G. Brazil: teachers development and incentives: a strategic framework. Washington: World Bank, 2000. Disponível em: <http:// www.worldbank.org>. Acesso em: 29 abr. 2008.

EVANGELISTA, O.; SHIROMA, E. O. Professor: protagonista e obstáculo da reforma. Educação e Pesquisa, São Paulo, v. 33, n. 3, p. 531-541, set./dez. 2007. DOI: 10.1590/S1517-97022007000300010

FNDEP. Fórum Nacional em Defesa da Escola Pública. Formar ou certificar? Muitas questões para reflexão. 2003. Disponível em: <http://www.andes.org.br>. Acesso em: 29 abr. 2008.

FREITAS, H. C. L. de. A reforma do Ensino Superior no campo da formação dos profissionais da educação básica: as políticas educacionais e o movimento dos educadores. Educação \& Sociedade, Campinas, v. 20, n. 68, p. 17-44, dez. 1999.

DOI: 10.1590/S0101-73301999000300002

As diretrizes para os cursos de formação de professores da educação básica. Pucviva, São Paulo, n. 13, p. 1-4, jul./set. 2001. Disponível em: <http://www. apropucsp.org.br/revista/r13_r07.htm>. Acesso em: 29 abr. 2008.

Formação de professores no Brasil: 10 anos de embate entre projetos de formação. In: Educação \& Sociedade, Campinas, v. 23, n. 80, p. 136-167, set. 2002. DOI: 10.1590/S0101-73302002008000009

Todo Educador Aprendendo (Lições do I Encontro Nacional). set. 2003a. Disponível em: <www. forgrad.org.br/arquivo/textoencontro_certificacao_ helena_freitas.doc>. Acesso em: 29 abr. 2008.

. Certificação docente e formação do educador: regulação e desprofissionalização. Educação \& Sociedade, Campinas, v. 24, n. 85, p. 1095-1124, dez. 2003b. DOI: 10.1590/S0101-73302003000400002

Certificação de professores: regulação e desprofissionalização do trabalho docente. Adusp, São Paulo, n. 32, p. 43-52, abr. 2004. Disponível em: <http:// www.adusp.org.br/revista/32/r32a04.pdf>. Acesso em: 29 abr. 2008.

A (nova) política de formação de professores: a prioridade postergada. Educação \& Sociedade, Campinas, v. 28, n. 100 - Especial, p. 1203-1230, out. 2007. DOI: 10.1590/S0101-73302007000300026

GENTILI, P. et al. Reforma educativa y luchas docentes en América Latina. Educação \& Sociedade, Campinas, v. 25, n. 89, p. 1251-1274, set./dez. 2004. DOI: 10.1590/S0101-73302004000400009
HERRÁN, C. A.; SALAZAR, C. U. Incentivos a escuelas y maestros: la experiencia colombiana. In: PEARLMAN, $M$. et al. Maestros en América Latina: nuevas perspectivas sobre su formación y desempeño. Santiago: PREAL-BID, 2004. p. 377-387. Disponível em: <http:// www.preal.org>. Acesso em: 22 maio 2010.

IG. Serra quer reajuste ligado a desempenho de professor. 4 ago. 2009. Disponível em:<http:// ultimosegundo.ig.com.br/brasil/serra+quer+re ajuste+ligado+a+desempenho+de+professor/ n1237625245618.html>. Acesso em: 12 fev. 2011.

MEC formaliza exame para carreira docente. 24 maio 2010. Disponível em: <http://ultimosegundo. ig.com.br/educacao/mec+formaliza+exame+para+carr eira+docente/n1237634237909.html>. Acesso em: 26 maio 2010.

MELLO, G. N. de. Social democracia e educação: teses para discussão. 2. ed. São Paulo: Cortez, Autores Associados, 1990.

Formação inicial de professores para a educação básica: uma (re)visão radical. São Paulo em Perspectiva, São Paulo, v. 14 n. 1, p. 98-110, jan./mar. 2000. DOI: 10.1590/S0102-88392000000100012

Uma vida de educadora. Disponível em: <http://www.namodemello.com.br/vida_educ.html>. Acesso em: 8 fev. 2011.

OCDE. Organização para Cooperação e Desenvolvimento Econômicos. Professores são importantes: atraindo, desenvolvendo e retendo professores eficazes. São Paulo: Moderna, 2006.

REZENDE, F. da C. A reforma do Estado em perspectiva comparada. In: SEMINÁRIO BALANÇO DAREFORMA DO ESTADO NO BRASIL. Balanço da reforma do Estado no Brasil: a nova gestão pública. Brasília: MP, SEGES, 2002. p. 223-233.

SANTOS, N. E. P. dos; FIDALGO, F. A centralidade da certificação de competências no Brasil. In: REUNIÃO ANUAL DA ANPED, 27., 2004, Caxambu. Anais... Caxambu, 2004. p. 1-17. Disponível em: <http://www. anped.org.br/reunioes/27/gt09/t0915.pdf>. Acesso em: 22 abr. 2008.

SCHNEIDER, M. C. Certificação de professores: contradições de uma política. 2009. 248 f. Dissertação (Mestrado em Educação) - Centro de Ciências da Educação, Universidade Federal de Santa Catarina, Florianópolis, 2009.

SINPRO-SP. Sindicato dos Professores de São Paulo. Adiado o exame de certificação de professores. Jornal dos Professores, São Paulo, n. 133, out. 2003. Disponível em: <http://www.sinprosp.org.br/jornal.asp?id_ jornal=465\&id_edicao_jornal=22>. Acesso em: 31 maio 2008.

Recebido em 30/01/2011

Versão final recebida em 20/03/2011

Aceito em 04/04/2011 